\title{
Applications and Prospects of Ultrasound-Assisted Extraction in Chinese Herbal Medicine
}

\author{
Aihua Sun ${ }^{1}$, Xiaoyan Chi ${ }^{1 *}$, Xiaoguang Yang ${ }^{2}$, Jiang Feng ${ }^{2}$, Yanmin $\mathrm{Li}^{1}$ and Juhua Zhou ${ }^{1 *}$ \\ ${ }^{1}$ Institute for Tumor Immunology, Ludong University School of Life Sciences, China \\ ${ }^{2}$ Hangzhou Hesti Biotechnology Co., China
}

\begin{abstract}
Ultrasound-assisted extraction method has become more attractive due to its several advantages such as low energy consumption, less extraction time, less active compound damage and high extraction yields as compared with conventional extraction methods. Ultrasound-assisted extraction has been successfully used in the extraction of various medicinal compounds including alkaloids, flavonoids, glycosides, phenolic compounds and polysaccharides from plants in laboratory investigations. The mechanisms, regulatory factors, advantages and disadvantages of ultrasoundassisted extraction method are discussed in this paper. It is expected that ultrasound-assisted extraction method will become popular in Chinese herbal medicine industries in the near future.
\end{abstract}

KEYWORDS: Ultrasound-assisted extraction; Medicinal compounds; Chinese herbal medicine

\section{INTRODUCTION}

Extraction of medicinal compounds from plants is a critical step in medical research, drug manufacture and clinical applications in Chinese herbal medicine. Traditional methods including impregnation, percolation, decoction, reflux extraction, continuous reflux extraction, steam distillation, sublimation and press method are commonly used in the extraction of medicinal compounds from plants Seidel [1]; Chua [2]; Al-Ramahi et al. [3]; Kong [4]. The disadvantages of these methods include time-consuming process, poor purity and low efficiency Mandal [5]; Dewanjee [6]; Lu [7]; Mura [8]. Ultrasound-assisted extraction (UAE) was first used in the isolation of alkaloids from Cinchona succirubra Head et al. [9] and has been increasingly used in the extraction of medicinal compounds from plants Zhao et al. [10]; Florez-Fernandez [11]; Jibril [12]. In this paper, recent advances in applications and prospects of ultrasound-assisted extraction in Chinese herbal medicine are discussed. It is expected that this method will be commercially used in the extraction of medicinal compounds from plants for drug manufacture and clinical applications in Chinese herbal medicine in the near future.

\section{MECHANISMS OF ULTRASOUND-ASSISTED EXTRACTION}

To extract medicinal compounds from plants, both cell wall and cell membrane must be destroyed. For this purpose, ultrasounds are used for cell disintegration in ultrasound-assisted extraction Lee [13]; Barba [14]. Ultrasounds are sound waves with frequencies from $20 \mathrm{kHz}$ up to several gigahertz, which are higher than the upper audible limit of human hearing Podder [15]. Ultrasound treatment has thermal effects Feng [16]; Kumcuoglu [17]; Wang [18]; plant materials and solvent absorb the energy
Quick Response Code:

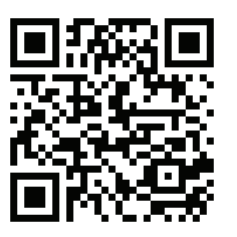

Address for correspondence: Juhua Zhou, Institute for Tumor Immunology, Ludong University School of Life Sciences, China

Xiaoyan Chi, Institute for Tumor Immunology, Ludong University School of Life Sciences, PR China

Received: August 01, 2019 Published: August 22, 2019

How to cite this article: Aihua S, Xiaoyan C, Xiaoguang Y, Jiang F, Yanmin L and Juhua Z, Applications and Prospects of Ultrasound-Assisted Extraction in Chinese Herbal Medicine. 2019 - 1(1) OAJBS.ID.000103. DOI: 10.38125/OAJBS.000103 
of the ultrasound waves and convert them into heat energy. The frequency, intensity and duration of ultrasound treatment affect the amount of heat generated in plant materials. This heat energy denatures proteins, destroys plant cells and increases the release of medicinal compounds from plant cells.

Ultrasound treatment also produces mechanical effects caused by the interaction between the ultrasonic waves, and the plant tissues and solvent Feng [16]. The mechanical effects of ultrasound include high-frequency vibration, radiation pressure and shear forces Sarvazyan [19]. They damage plant cells and tissues and denature proteins Riesz [20]; Altemimi [21]. Thus, these mechanical effects facilitate a more complete penetration of solvent into the plant tissues and cell compartments, and extraction of medicinal compounds from plant cells.

In addition, ultrasonic waves generate cavitation and thus destroy cell wall and cell membrane, facilitating the release of medicinal compounds from plant cells and tissues Riesz [20]; Wu [21]; Kumcuoglu [17]; Bashi [22]. The ultrasonic waves generate alternating high-pressure and low-pressure cycles in liquid media. During the low-pressure cycle, high-intensity ultrasonic waves produce small vacuum bubbles in the liquid. During the high-pressure cycle, small vacuum bubbles collapse destructively. This phenomenon is called cavitation $\mathrm{Xu}$ et al. [23]. Implosion of cavitation bubbles may also generate liquid jets with a high speed of up to $280 \mathrm{~m} / \mathrm{s}$, resulting in shear forces Williams [24]. The shear forces break the cell wall and cell membrane mechanically, and thus promote cellular component release.

\section{CHARACTERISTICS OF ULTRASOUND-ASSISTED EXTRACTION}

As stated above, ultrasound treatment has thermal, mechanical and cavitation effects in ultrasound-assisted extraction. Thus, this method may have unique features and advantages as compared with the traditional methods in the extraction of medicinal compounds from plants.

\section{High efficiency}

Ultrasound-assisted extraction has high extraction efficiency in the extraction of medicinal compounds from plants Xu et al. [25]; Zhang [26]. The traditional methods usually take a couple of days, whereas ultrasound-assisted extraction could be finished within several hours for the extraction of medicinal compounds from plants Florez-Fernandez, [11]. For example, ultrasound-assisted extraction has higher extraction efficiency in the extraction of isoflavone from Puerariae Lobatae Radix than the traditional methods $\mathrm{Wu}$ [27].

\section{Low energy consumption}

The energy consumption of ultrasound-assisted extraction is less by far than the traditional methods in the extraction of medicinal compounds from plants Petigny [28]; Kazemi [29]; Zhu et al. [30].

\section{High qualities}

The medicinal compounds extracted from plants by ultrasound-assisted extraction have better qualities Petigny [28]. In comparison with the traditional methods, the ultrasound-assisted extraction takes less time and thus keeps minimal degradation and contamination of medicinal compounds during extraction. For example, ultrasound-assisted extraction of essential oil from fresh garlic (Allium sativum) cloves resulted in less degradation of thermal-sensitive molecules as compared with the traditional distillation extraction methods Kimbaris [31].

\section{High yields}

The yields of plant medicinal compounds extracted by ultrasound-assisted extraction are usually higher Petigny, [28]; Kazemi [29]; Dhanani [32]. Ultrasound treatment generates mechanical and cavitation effects, leading to the efficient disintegration of plant cells and increased release of medicinal compounds.

\section{Extensive application}

The choice of specific traditional method used in the extraction of medicinal compounds from plants depends on the molecular weight, solubility and heat-stability of targeted medicinal component. Ultrasound-assisted extraction, however, may be used in the extraction of varieties of targeted medicinal compounds such as alkaloids Wang [33], anthraquinones Jibril [12], flavonoids Zhou [34]; Pinela [35], glycosides Dong [36], oil Senrayan [37], pectin (Grassino [38]), phenolic compounds Um [39]; Wang [40] and polysaccharides Wang [33]; Cheng et al. [41], and thus has an extensive application in the extraction of medicinal compounds from plants.

\section{Automation}

Ultrasound parameters such as frequency, intensity and duration can be easily adjusted and controlled in ultrasoundassisted extraction Altemimi [21]; Kazemi [29]. Therefore, ultrasound-assisted method may be automated in the extraction of medicinal compounds from plants Zhang [42].

\section{High standard}

The facilities used in ultrasound-assisted extraction are of high quality and may meet the requirement of Good Manufacturing Practice (GMP) in the extraction of medicinal compounds from plants in medical industry (Gambaro [43]; Singanusong [44].

\section{FACTORS ASSOCIATED WITH ULTRASOUND- ASSISTED EXTRACTION}

The ultrasound-assisted extraction has unique features and advantages as compared with the traditional methods in the extraction of medicinal compounds from plants. Nevertheless, several important factors significantly affect the quality and yield of the extracted medicinal compounds from plants.

\section{Ultrasonic frequency}

The ultrasonic frequency impacts the efficiency of ultrasoundassisted extraction in the extraction of medicinal compounds from plants Dranca [45]. In general, the low ultrasonic frequency generates greater mechanical and cavitation effects, leading to increased efficacies of ultrasound-assisted extraction Tran [46]; Xin [47]. An exception has been reported when use of higher ultrasonic 
frequency resulted in better efficiency of ultrasound-assisted extraction of phenolic compounds from Phyllanthus emblica Tsai [48]. The optimal ultrasonic frequencies differ for different plant tissues in ultrasound-assisted extraction of specific medicinal components. An ultrasonic frequency of $40 \mathrm{kHz}$ is suitable for the ultrasound-assisted extraction of apigenin, baicalin and luteolin compounds from the air-dried whole plants of Scutellaria barbata D. Don Wei [49]. An ultrasonic frequency of $60 \mathrm{kHz}$ is better than 20 $\mathrm{kHz}$ and $100 \mathrm{kHz}$ for ultrasound-assisted extraction of hesperidin from Penggan (Citrus reticulata) peel Ma [50].

\section{Duration of ultrasound treatment}

The duration of ultrasound treatment in the ultrasoundassisted extraction is usually much shorter than the traditional methods Celli [51]. Generally, the duration of ultrasound treatment is 20-45 minutes in the ultrasound-assisted extraction of medicinal compounds from plants. An ultrasound treatment for $30 \mathrm{~min}$ is suitable for the ultrasound-assisted extraction of apigenin, baicalin and luteolin compounds from Scutellaria barbata D. Don Wei [49]. Ultrasound treatment for $44.85 \mathrm{~min}$ is the optimal condition for total monomeric anthocyanin extraction from eggplant (Solanum melongena L.) peel, whereas $57.5 \mathrm{~min}$ is the optimal extraction time for phenolic compounds extraction from eggplant peel Dranca [45]

\section{Duty cycle of ultrasound}

The duty cycle of ultrasound refers to the percentage of time that ultrasound is being generated (pulse duration) over one pulse period. The duty cycle of ultrasound dramatically impinges on the cavitation effects and thus affects the efficiency of ultrasoundassisted extraction Dey [52]. A duty cycle of 75\% (intermittent sonication, 90 s of pulse followed by 30s of no pulse) is suitable for the ultrasound-assisted extraction of apigenin, baicalin and luteolin compounds from Scutellaria barbata D. Don Wei [49], whereas a duty cycle of $50 \%$ is more efficient for ultrasound-assisted extraction of phenolic compounds from pomegranate peel Kazemi [29].

\section{Solvent}

Different medicinal compounds have different solubilities in different solvents. For instance, saponins and polysaccharides have good solubility in water Xie et al. [53]; Zhang, Qiao [54], whereas phenolic compounds such as anthocyanins and chlorogenic acid have good solubility in ethanol (Liu, Wei et al. 2013; Tan, Wang et al. 2014). Thus, the choice of solvent depends on the solubility of targeted medicinal compounds in ultrasound-assisted extraction. An ethanol concentration of $60 \%(\mathrm{v} / \mathrm{v})$ is suitable for the ultrasound-assisted extraction of apigenin, baicalin and luteolin compounds from Scutellaria barbata D Don Wei et al. [49]. Methanol is the best solvent for ultrasound-assisted extraction of hesperidin from Penggan (Citrus reticulata) peel compared with ethanol or isopropanol Ma [50].

\section{Features of plant materials}

It has been documented that the parameters for extracting medicinal compounds from various plants are different. These differences may be due to the unique features of different plant materials including tensile strength, flexibility, shape, density, and surface morphology. The unique features of plant materials are determined by the plant cell wall structures, which are composed of cellulose, hemicelluloses, lignin, and pectin. Different plant materials contain different types and amount of cellulose, hemicelluloses, lignin, and pectin. These differences affect the efficiency of ultrasound-assisted extraction of medicinal compounds from plants.

\section{Size of plant materials}

Plant materials are usually minced into tiny granules before they are used in ultrasound-assisted extraction. In general, the smaller the granules of plant materials the higher the efficiency of ultrasound-assisted extraction. The granules of plant materials with $0.250-0.149 \mathrm{~mm}$ in diameter are appropriate for ultrasoundassisted extraction of medicinal compounds from plants. A mean plant particle size of $0.355 \mathrm{~mm}$ is suitable for the ultrasoundassisted extraction of apigenin, baicalin and luteolin compounds from the air-dried whole plants of Scutellaria barbata D. Don Wei [49].

\section{Immersion time}

The immersion time of plant tissues in the solvent affects the efficiency of ultrasound-assisted extraction. Short-time immersion makes incomplete extraction of medicinal compounds from plant tissues, whereas a prolonged period of immersion time also hinders the transfer of medicinal compounds from plant cells into the solvent and impedes the efficiency of ultrasound-assisted extraction. The optimal immersion time for different plant tissues and specific medicinal component in ultrasound-assisted extraction should be determined experimentally.

\section{Extraction temperature}

Ultrasound treatment has thermal effects, which influence the efficiency of ultrasound-assisted extraction of medicinal compounds from plants. Extraction temperature itself also affects the extraction efficiency. Therefore, the extraction temperature may be different for ultrasound-assisted extraction of different medicinal compounds from different plants. For instance, $80{ }^{\circ} \mathrm{C}$ is optimal to achieve maximum yield of flavonoids from Sophora flavescens Zhou [34], and $50{ }^{\circ} \mathrm{C}$ to extract arabinoxylan from wheat bran Sun [55].

\section{APPLICATIONS OF ULTRASOUND-ASSISTED EXTRACTION}

Ultrasound-assisted extraction may have several advantages in the extraction of medicinal compounds from plants as compared with the traditional methods Petigny [28]; Kazemi [29]; Zhang et al. [26]. Thus, ultrasound-assisted extraction has great applications in Chinese herbal medicine.

\section{Extraction of alkaloids}

Alkaloids are a group of chemical compounds containing basic nitrogen atoms, which are naturally present in plants, animals and other organisms Derosa [56]. They have various medicinal activities such as antibacterial, antimalarial, antiasthma and anticancer Imperatore [57]; Pervaiz et al. [58]; Promchai [59]. 
Alkaloids are usually extracted from different plants by acid-base extraction Rujjanawate [60]; Vieira [61]. However, ultrasoundassisted extraction of fangchinoline and tetrandrine alkaloids from Stephaniae tetrandrae has a much shorter extraction time (from 6 $\mathrm{h}$ to $40 \mathrm{~min}$ ) and significantly increased efficiency (approximately $30 \%$ improvement) as compared with traditional refluent extraction method Zhang [62]. Ultrasound-assisted extraction is the most suitable method for steroidal alkaloids from potato peel waste Hossain [63] and for the extraction of ergot alkaloids from seeds of the genus Ipomoea plants Nowak [64].

\section{Extraction of artemisinin}

Artemisinin is a sesquiterpene lactone containing an unusual peroxide bridge and has a therapeutic activity against Plasmodium falciparum malaria Klayman [65]; White [66]. It was isolated from the plant Artemisia annua L. Klayman [67]. Ultrasound-assisted extraction is an effective method in the isolation of artemisinin from Artemisia annua leaves Chemat [68].

\section{Extraction of carotenoids}

Carotenoids are one of plant pigment classes and the dominant pigment in autumn leaf coloration of $15-30 \%$ of trees. Their functions include absorption of light energy for use in photosynthesis and protection of chlorophyll from photo damage Chen [69]; Niedzwiedzki [70]. Carotenoids have also antioxidation activities Rangani [71]. It has been reported that ultrasoundassisted extraction using vegetable oils could be used in the extraction of carotenoids from peach palm fruit and pomegranate peels Ordonez-Santos et al. [72]; Goula [73].

\section{Extraction of coumarins}

Ultrasound-assisted extraction method is also used in the extraction of coumarins from plants. Ultrasound-assisted extraction of total coumarins from Cortex Fraxini, the barks of Fraxinus chinensis Roxb, is much better than the classic Soxhlet extraction in terms of processing time, energy cost and extraction efficiency Xiong [74]. The optimal conditions for the extraction of total coumarins from Cortex Fraxini include $60 \%$ ethanol, a ratio of solid to liquid 1:10 (W/V), ultrasonic frequency $175 \mathrm{~W}$, extraction temperature of $50^{\circ} \mathrm{C}$ and extraction time of $40 \mathrm{~min}$. The extraction rate of total coumarins is $6.283 \%$ under the optimal extraction conditions.

\section{Extraction of flavonoids}

Flavonoids, which belong to a polyphenolic subgroup, are usually present in plants and fungi. So far, more than 6,000 flavonoids have been identified, and quercetin, kaempferol, catechins and anthocyanidins are examples of the best-known flavonoids Konrad [75]. They may be divided into six subgroups: chalcones, flavones, flavonols, flavanones, anthocyanins and isoflavonoids Konrad [75]; Jiang [76]. Flavonoids have antioxidant, anti-inflammatory, and anti-cancer biological activities and provide vibrant food coloring Nakatsuka [77]; Martinez-Perez [78]; Konrad [75]. They have also great implications in Chinese herbal medicine Tang et al. [79]; Zheleva-Dimitrova [80]. Ultrasound-assisted extraction is often used in the extraction of flavonoids from plants Pan [81]; Wang [82]; Tomaz [83].
Extraction of anthocyanins: Anthocyanins belong to a subgroup of flavonoids Hassellund [85]. Anthocyanins have been found to improve heart health, boost cancer defense, fight free radicals, inhibit virus and suppress inflammation (Hassellund [85]; Sehitoglu [85]; Cassidy [86]. Ultrasound-assisted extraction is an effective method for the extraction of anthocyanins from mulberry using $63.8 \%$ methanol with $1 \%(\mathrm{v} / \mathrm{v})$ trifluoroacetic acid (TFA), $43.2^{\circ} \mathrm{C}$ extraction temperature, $23.8(\mathrm{v} / \mathrm{w})$ liquid-to-solid ratio, and 40 min extraction time Zou [87]. Ultrasound-assisted extraction is also a suitable method for the extraction of anthocyanins from plant materials such as blueberry He [88], haskap berries Celli [51] and Nitraria tangutorun Bobr. seed meal Sang [89].

Extraction of baicalin: Baicalin is a flavone glycoside, which may have an anti-inflammatory activity and anti-atherosclerotic potential and promote hippocampal neurogenesis Yang [90]; Yu et al. [91]; Zhang [92]. Heat-reflux and ultrasound-assisted extraction method are superior to traditional heat-reflux extraction method regarding the extraction time, extraction temperature, solvent consumption and yields in the extraction of baicalin from Scutellaria barbata D Don Wei [49]. The optimal conditions for the extraction of baicalin from Scutellaria barbata D. Don includes an ultrasonic frequency of $40 \mathrm{kHz}$, power of $185 \mathrm{~W}$, duty cycle of $75 \%$ (intermittent sonication), mean particle size of $0.355 \mathrm{~mm}$, extraction temperature of $50 \mathrm{oC}$, ratio of solvent to raw material of $12: 1(\mathrm{~mL} / \mathrm{g})$, ethanol concentration of $60 \%(\mathrm{v} / \mathrm{v})$, and extraction time of $30 \mathrm{~min}$ and three cycles.

Extraction of breviscapine: Breviscapine is a flavonoid extracted from plants and has therapeutic benefits for patients with diabetic nephropathy, cardiovascular and cerebrovascular diseases Ji [93]; Liu [94]. Ultrasound-assisted extraction is a simple, inexpensive and effective method for the extraction of breviscapine from Erigeron breviscapus He ME [95]. The optimal conditions include extraction time of $24.5 \mathrm{~min}$, ethanol concentration of $74.7 \%$ and a ratio of solvent volume to plant material mass of $19.8(\mathrm{~mL} / \mathrm{g})$.

Extraction of isoflavonoids: Puerarin is an isoflavonoid extracted from the root of Pueraria lobata (Wild.) Ohwi Yeung [96]. It has been widely used in Chinese herbal medicine due to its numerous beneficial actions for cardiovascular diseases, acute dysentery, hypertension, alcoholism, deafness, cancer and diarrhea Jintao [97]. Ultrasound-assisted extraction could be used in the extraction of puerarin and total isoflavones from the root of Pueraria lobata (Wild.) Ohwi Fan [98]; Wu [99]. The optimal extraction conditions include ethanol concentration of $71.35 \%$, extraction time of $49.08 \mathrm{~min}$ and a solvent-to-material ratio of 21.72 for puerarin extraction from the root of Pueraria lobata, whereas the optimal conditions for total isoflavone extraction include $80 \%$ ethanol, extraction time $55 \mathrm{~min}$ and a solvent-to-material ratio $12.81 \mathrm{Wu}[99]$.

\section{EXTRACTION OF GLYCOSIDES}

It has been known that glycosides have numerous important biological functions Diederich [100]; Xue [101]. Thus, glycosides from plants are often used as pharmaceutical drugs Oerther [102]. Glycosides may also be extracted from plants by ultrasoundassisted extraction method Dong [36]. 


\section{Extraction of geniposide}

Geniposide is a glycoside, which is the important bioactive component extracted from the fruits of Gardenia jasminoides Ellis Cai [103]. Geniposide has been shown to possess anti-inflammatory, antioxidant, anti-carcinogenic and anti-angiogenic activities Miao [104]; Huang [105]. Ultrasound-assisted extraction could be successfully used in the extraction of geniposide from Gardenia jasminoides Ellis Wang [27].

\section{Extraction of paeoniflorin}

Paeoniflorin is a glycoside and has numerous biological functions including anti-cancer and neuroprotection activities Hao [106]; Liu [107]. Paeoniflorin could be isolated from the root of Paeonia lactiflora by ultrasound-assisted extraction Xie et al. [108]; Liu et al. [42].

\section{Extraction of phillyrin}

Phillyrin is a glycoside found in plants and fungi, which possesses anti-bacteria, anti-viruses, anti-inflammation and antioxidation properties Xia [109]; Wei [110]; Qi [111]. Phillyrin can be extracted from Forsythia suspensa (Thunb.) Vahl by ultrasoundassisted extraction and the optimal extraction conditions include $20 \%$ methanol, solvent-to-material ratio 10 , ultrasound power $600 \mathrm{~W}$, ultrasound frequency $40 \mathrm{kHz}$, extraction temperature $60 \stackrel{\circ}{\circ} \mathrm{C}$ and extraction time $60 \mathrm{~min}$ Xia [109].

\section{Extraction of saponins}

Saponins are a group of amphipathic glycosides found in plants. They have anti-cancer, anti-inflammatory, antioxidant, expectorant and vasoprotective activities Kang [112]; Koczurkiewicz [113]. Ultrasound-assisted extraction is a simple and effective method to extract saponins from different types of ginseng and other Chinese medical herbs Wu [114]; Liu [115].

\section{EXTRACTION OF LIGNANS}

Lignans are a group of polyphenolic compounds present in plants. It has been shown that lignans have anti-cancer, antiinflammation, anti-oxidation and neuroprotection activities Adfa [116]; Hu [117]; Li [118]; Teponno [119]. Ultrasound-assisted extraction has been successfully used in the extraction of lignans such as honokiol and magnolol from Magnoliae officinalis Zhang [120]. Ultrasound-assisted extract in combination with an aqueous two-phase system is much better in the extraction of lignans from Schisandra chinensis and Zanthoxylum armatum Guo [121]; $\mathrm{Su}$ [122]. For the extraction of lignans from the root and stem mixture of Zanthoxylum armatum, the optimal conditions include an aqueous two phase system of $20 \%$ n-propanol and $24 \%$ (NH4)2SO4 in combination with ultrasonic-assisted extraction of a solvent to solid ratio $15: 1$, ultrasonic power $250 \mathrm{~W}$, extraction temperature $40^{\circ} \mathrm{C}$ and extraction time $55 \mathrm{~min}$. To extract lignans from Schisandra chinensis seeds, 25\% (w/w) (NH4)2SO4 and 19\% $(\mathrm{w} / \mathrm{w})$ ethanol are combined with the optimal ultrasound-assisted extraction conditions of a solid-liquid ratio 20:1, ultrasonic power 800W and extraction time $61.1 \mathrm{~min}$ Guo [121].

\section{EXTRACTION OF OILS}

Oils extracted from plants have several medicinal applications
Li [123]; Kasrati [124]; Wangchuk [125]; Uma [126]. Ultrasoundassisted extraction is the most effective method for the extraction of essential oils from Ligusticum chuanxiong as compared with supercritical fluid extraction, Soxhlet extraction and hydrodistillation extraction Yang [127]. Ultrasound-assisted extraction can be used in the extraction of oils from grape and papaya seeds Da Porto [128]; Samaram [129]. However, ultrasound-assisted extraction may not be a suitable method for extracting volatile oils from Rhizoma Curcumae Zhang [130].

\section{EXTRACTION OF PHENOLIC COMPOUNDS}

Phenolic compounds may be divided into two categories, simple phenols and polyphenols. Phenolic compounds from medicinal plants usually contain phenolic acids, flavonoids, tannins, stilbenes, curcuminoids, coumarins, lignans and quinones. Phenolic compounds are used in medicine due to their antioxidant, anticarcinogenic, antimutagenic and anti-inflammatory activities Huang [131]; Zhu [18]. Ultrasound-assisted extraction can be efficiently used in the extraction of total phenolic compounds from plants including Amygdalus persica, Cucurbita moschata, Inula helenium, Myrcia amazonica DC and Vaccinium ashei Wang et al. [132]; Altemimi [21]; de Morais Rodrigues [133]; He [88].

\section{EXTRACTION OF POLYSACCHARIDES}

Polysaccharides are polymers of three or more monosaccharides. Polysaccharides have many biological functions such as anti-tumor, anti-virus, immune modulation and antioxidative activities Feng et al. [134]; Nie et al. [135]; Wang et al. [136]; Dan Liu et al. [137]. Studies have shown that ultrasound-assisted extraction may be effectively used in the extraction of polysaccharides from a variety of plants You [138]; Jia [139]. Zhang et al. [140]; Ren [141]. The optimal conditions for extraction of polysaccharides from different plants are not identical. For instance, the optimal conditions for ultrasound-assisted extraction of polysaccharides from mulberry fruits include a ratio of water to raw material 40.25, extraction temperature $69^{\circ} \mathrm{C}$, ultrasonic power $190 \mathrm{~W}$ and extraction time 75 min, whereas those for the extraction of polysaccharides from Artemisia sphaerocephala Krasch seeds include a solid-liquid ratio $64: 1$, extraction temperature $64^{\circ} \mathrm{C}$, ultrasonic power $243 \mathrm{~W}$ and extraction time $125 \mathrm{~min}$ You et al. [138].

As structural polysaccharides, pectin is present in the primary cell walls of plants. Pectin is usually used in food preparation and medicine Eliaz [142]; Delphi [143]; Ueberall [144]. Ultrasoundassisted extraction can be efficiently used in the extraction of pectin from mango, tomato and Artocarpus heterophyllus fruit peels Grassino [38]; Wang [145]; Moorthy [146]. In addition, ultrasoundassisted extraction is an effective method for extraction of $\beta$ - $d$ glucan from hull-less barley Koocheki et al. [147].

\section{EXTRACTION OF STEROIDS}

Steroids are organic molecules containing a four-ring core. Steroids possess various biological functions and clinical benefits including cytotoxicity, antibacteria, antifungi, antiviruses and antiinflammation Kuthubutheen [148]; McCabe [149]; Zubair [150]. Hundreds of steroids are present in plants, and thus steroids may be isolated from plants by ultrasound-assisted extraction (Schinor, Salvador et al. 2004). For instance, two steroids ( $\beta$-sistosterol and 
stigmasterol) have been purified from from Annona glabra leaves by ultrasound-assisted extraction Matsumoto [151].

\section{EXTRACTION OF TAXOL}

Taxol is a chemotherapy drug, which is extensively used in the treatment of cancer patients Lemstrova, [152]; Chen [153]. It is usually isolated from the bark, roots, stems and leaves of plants from the genus Taxus including Taxus baccata, Taxus brevifolia, Taxus chinensis var. mairei, Taxus cuspidate and Taxus madia Dong [154]. Yew plants in the genus Taxus usually grow slowly and contain very low amounts of taxol Mayol [155]; Gong et al. [156]. In addition, conventional extraction methods have a low efficiency in the isolation of taxol from yew plants Kim [157]. Ultrasoundassisted method with $50 \%$ ethanol is an efficient method to extract taxol from Taxus cuspidate Xiao, Lao et al. [158].

\section{PROSPECTS OF ULTRASOUND-ASSISTED EXTRACTION}

As compared with conventional extraction methods, ultrasoundassisted extraction has several advantages such as low energy consumption, less extraction time, less active compound damage and high extraction yields. Thus, ultrasound-assisted extraction has become one of most attractive methods used in Chinese herbal medicine. There are several limitations, however, which require further investigations for useful and effective applications in Chinese herbal medicine.

So far, majority of reports focused on the optimization of ultrasound-assisted extraction conditions used in the isolation of medicinal compounds from plants Bashi [22]; de Morais Rodrigues [133]; Dranca [45]; Kazemi [29]; Meullemiestre, [159]; Nour [160]; Alves Monteath [161]. Thus, ultrasound-assisted extraction used in the isolation of medicinal compounds from plants was restricted to laboratory investigations. Further studies will be required for the application of ultrasound-assisted extraction for the large-scale isolation of medicinal compounds from plants.

Very few studies have evaluated the biological functions of medicinal compounds isolated from plants by ultrasound-assisted extraction method. The flavonoids isolated from Stachys parviflora L. using ultrasound-assisted extraction possess significant antioxidant activities Bashi [22]. Polysaccharides isolated from Artemisia selengensis Turcz by ultrasound-assisted extraction have anti-tumor activity Wang et al. [162]. With these limited studies, evaluation of the biological functions of medicinal compounds isolated from plants by ultrasound-assisted extraction method warrants further investigations.

The advantages of ultrasound-assisted extraction for isolating medicinal compounds from plants are well-documented Ghitescu [163]; Chemat [164]; Espada-Bellido [165]. However, the underlying mechanisms of these benefits are not clearly understood Saleh [166]. We believe that a dissection of the mechanisms is critical for ultrasound-assisted extraction to be applied, improved and expanded in relation to medicinal compound extraction, which is of enormous relevance to research and industry in Chinese herbal medicine. It is anticipated that ultrasound-assisted extraction method will be extensively used in Chinese herbal medicine industries [167-173].

\section{ACKNOWLEDGEMENT}

This work was supported by a grant (\#J14LK53 to XC) from the Department of Education of Shandong Province and "Taishan Scholar" Special Fund (\#tshw20120718 to JZ) from the Shandong Government, China. The funding sources were not involved in study design, the collection, analysis and interpretation of data, the writing of the report and the decision to submit the article for publication.

\section{REFERENCES}

1. Seidel V (2012) Initial and bulk extraction of natural products isolation. Methods Mol Biol 864: 27-41.

2. Chua LS (2013) A review on plant-based rutin extraction methods and its pharmacological activities. J Ethnopharmacol 150(3): 805-817.

3. Al-Ramahi R, Jaradat N, Zaid AN, Vincieri FF, Asmaa M (2014) Medicinal herbs and methodologies for their pharmaceutical compounding in the West Bank/Palestine. Complement Ther Clin Pract 20(4): 280-284.

4. Kong F, Yu S, Bi Y, Huang X, Huang M (2016) Optimization of process parameters and kinetic model of enzymatic extraction of polyphenols from Lonicerae Flos. Pharmacogn Mag 12(45): 70-74.

5. Mandal V, Dewanjee S, Mandal SC (2009) Role of modifier in microwave assisted extraction of oleanolic acid from Gymnema sylvestre: application of green extraction technology for botanicals. Nat Prod Commun 4(8): 1047-1052.

6. Mandal V, Dewanjee S, Sahu R, Mandal SC (2009) Design and optimization of ultrasound assisted extraction of curcumin as an effective alternative for conventional solid liquid extraction of natural products. Nat Prod Commun 4(1): 95-100.

7. Lu C, Wang H, Lv W, Ma C, Lou Z, et al. (2012) Ionic liquid-based ultrasonic/microwave-assisted extraction combined with UPLC-MS-MS for the determination of tannins in Galla chinensis. Nat Prod Res 26(19): 1842-1847.

8. Mura M, Palmieri D, Garella D, Di Stilo A, Perego P, et al. (2015) Simultaneous ultrasound-assisted water extraction and betacyclodextrin encapsulation of polyphenols from Mangifera indica stem bark in counteracting TNFalpha-induced endothelial dysfunction. Nat Prod Res 29(17): 1657-1663.

9. Head WF, Beal HM, Lauter WM (1956) Ultrasonic extraction of Cinchona succirubra. J Am Pharm Assoc Am Pharm Assoc 45(4): 239-242.

10. Zhao YM, Yang JM, Liu YH, Zhao M, Wang J, et al. (2018) Ultrasound assisted extraction of polysaccharides from Lentinus edodes and its anti-hepatitis B activity in vitro. Int J Biol Macromol 107(Pt B): 2217 2223.

11. Flórez-Fernández N, Domínguez H, Torres MD (2019) A green approach for alginate extraction from Sargassum muticum brown seaweed using ultrasound-assisted technique. Int J Biol Macromol 124: 451-459.

12. Jibril S, Basar N, Sirat HM, Wahab RA, Mahat NA, et al. (2019) Application of box-behnken design for ultrasound-assisted extraction and recycling preparative HPLC for isolation of anthraquinones from Cassia singueana. Phytochem Anal 30(1): 101-109.

13. Lee K, Chantrasakdakul P, Kim D, Kong M, Park KY (2014) Ultrasound pretreatment of filamentous algal biomass for enhanced biogas production. Waste Manag 34(6): 1035-1040.

14. Barba FJ, Grimi N, Vorobiev E (2015) Evaluating the potential of cell disruption technologies for green selective extraction of antioxidant compounds from Stevia rebaudiana Bertoni leaves. J Food Eng 149(2015): 222-228.

15. Podder D, Sasmal S, Halder D (2015) Sonication responsive gelator: Synthesis and applications. Current Organic Synthesis 12(4): 440-456.

16. Feng F, Mal A, Kabo M, Wang JC, Bar-Cohen Y (2005) The mechanical and thermal effects of focused ultrasound in a model biological material. J Acoust Soc Am 117(1): 2347-2355. 
17. Kumcuoglu S, Yilmaz T, Tavman S (2014) Ultrasound assisted extraction of lycopene from tomato processing wastes. J Food Sci Technol 51(12): 4102-4107.

18. Zhu PF, Dai Z, Wang B, Wei X, Yu HF, et al. (2017) The anticancer activities phenolic amides from the stem of lycium barbarum. Nat Prod Bioprospect 7(6): 421-431.

19. Sarvazyan AP, Rudenko OV, Nyborg WL (2010) Biomedical applications of radiation force of ultrasound: historical roots and physical basis. Ultrasound Med Biol 36(9): 1379-1394.

20. Riesz P, Kondo T (1992) Free radical formation induced by ultrasound and its biological implications. Free Radic Biol Med 13(3): 247-270.

21. Altemimi A, Watson DG, Choudhary R, Dasari MR, Lightfoot DA (2016) Ultrasound assisted extraction of phenolic compounds from peaches and pumpkins. PLoS One 11(2): e0148758.

22. Bashi DS, Dowom SA, Bazzaz BS, Khanzadeh F, Soheili V, et al. (2016) Evaluation, prediction and optimization the ultrasound-assisted extraction method using response surface methodology: antioxidant and biological properties of Stachys parviflora L. Iran J Basic Med Sci 19(5): 529-541.

23. Xu WW, Tzanakis I, Srirangam P, Mirihanage WU, Eskin DG, et al. (2016) Synchrotron quantification of ultrasound cavitation and bubble dynamics in Al-10Cu melts. Ultrason Sonochem 31: 355-361.

24. Williams PR, Williams PM, Brown SWJ (1998) Cavitation phenomena in water involving the reflection of ultrasound pulses from a free surface, or from flexible membranes. Phys Med Biol 43(10): 3101-3111.

25. Xu DP, Zheng J, Zhou Y, Li Y, Li S, et al. (2016) Extraction of natura antioxidants from the thelephora ganbajun mushroom by an ultrasoundassisted extraction technique and evaluation of antiproliferative activity of the extract against human cancer cells. Int J Mol Sci 17(10).

26. Zhang S, Liu Q, Luo H, Chen P, Wu X, et al. (2016) UFLC-MS/MS analysis of four tanshinone components in Salvia miltiorrhizae after ultrasoundassisted extraction. J Chromatogr B Analyt Technol Biomed Life Sci 1017-1018: 204-210.

27. Wang XS, Wu YF, Dai SL, Chen R, Shao Y (2012) Ultrasound-assisted extraction of geniposide from Gardenia jasminoides. Ultrason Sonochem 19(6): 1155-1159.

28. Petigny L, Périno-Issartier S, Wajsman J, Chemat F (2013) Batch and Continuous Ultrasound Assisted Extraction of Boldo Leaves (Peumus boldus Mol.). Int J Mol Sci 14(3): 5750-5764.

29. Kazemi M, Karim R, Mirhosseini H, Abdul Hamid A (2016) Optimization of pulsed ultrasound-assisted technique for extraction of phenolics from pomegranate peel of malas variety: Punicalagin and hydroxybenzoic acids. Food Chem 206: 156-166.

30. Zhu Z, Guan Q, Koubaa M, Barba FJ, Roohinejad, et al. (2017) HPLC-DADESI-MS (2) analytical profile of extracts obtained from purple sweet potato after green ultrasound-assisted extraction. Food Chem 215: 391400.

31. Kimbaris AC, Siatis NG, Daferera DJ, Tarantilis PA, Pappas CS, et al. (2006) Comparison of distillation and ultrasound-assisted extraction methods for the isolation of sensitive aroma compounds from garlic (Allium sativum). Ultrason Sonochem 13(1): 54-60.

32. Dhanani T, Singh R, Reddy N, Trivedi A1, Kumar S (2017) Comparison on extraction yield of sennoside A and sennoside B from senna (Cassia angustifolia) using conventional and non-conventional extraction techniques and their quantification using a validated HPLC-PDA detection method. Nat Prod Res 31(9): 1097-1101.

33. Wang H, Tong Y, Li W, Zhang X, Gao X (2018) Enhanced ultrasoundassisted enzymatic hydrolysis extraction of quinolizidine alkaloids from Sophora alopecuroides L. seeds. J Nat Med 72(2): 424-432.

34. Zhou J, Zhang L, Li Q Jin W, Chen W, et al. (2018) Simultaneous optimization for ultrasound-assisted extraction and antioxidant activity of flavonoids from sophora flavescens using response surface methodology. Molecules 24(1).

35. Pinela J, Prieto MA, Pereira E, Jabeur I, Barreiro MF, et al. (2019)
Optimization of heat- and ultrasound-assisted extraction of anthocyanins from Hibiscus sabdariffa calyces for natural food colorants. Food Chem 275: 309-321.

36. Dong B, Yuan X, Zhao Q Feng Q, Liu B, et al. (2015) Ultrasound-assisted aqueous two-phase extraction of phenylethanoid glycosides from Cistanche deserticola YC Ma stems. J Sep Sci 38(7): 1194-1203.

37. Senrayan J, Venkatachalam S (2019) Optimization of ultrasound-assisted solvent extraction (UASE) based on oil yield, antioxidant activity and evaluation of fatty acid composition and thermal stability of Coriandrum sativum L. seed oil. Food Sci Biotechnol 28(2): 377-386.

38. Grassino AN, Brnčić M, Vikić-Topić D, Roca S, Dent M, et al. (2016) Ultrasound assisted extraction and characterization of pectin from tomato waste. Food Chem 198: 93-100.

39. Um M, Han TH, Lee JW (2018) Ultrasound-assisted extraction and antioxidant activity of phenolic and flavonoid compounds and ascorbic acid from rugosa rose (Rosa rugosa Thunb.) fruit. Food Sci Biotechnol 27(2): 375-382

40. Wang C, Tallian C, Su J, Vielnascher R, Silva C, et al. (2018) Ultrasoundassisted extraction of hemicellulose and phenolic compounds from bamboo bast fiber powder. PLoS One 13(6): e0197537.

41. Wang L, Cheng L, Liu F, Li T, Yu Z, et al. (2018) Optimization of ultrasoundassisted extraction and structural characterization of the polysaccharide from pumpkin (cucurbita moschata) seeds. Molecules 23(5).

42. Zhang Y, Liu C, Li J, Qi Y, Li Y, et al. (2015) Development of ultrasoundassisted dynamic extraction and its combination with CCC and CPC for simultaneous extraction and isolation of phytochemicals. Ultrason Sonochem 26: 111-118

43. Gambaro V, Minghetti P, Arnoldi S, Colombo ML, Dell'acqua L, et al. (2012) Analysis of fluid extracts obtained from Papaver rhoeas petals contaminated with Papaver bracteatum petals. Planta Med 78(12): 1395-1398.

44. Singanusong R, Nipornram S, Tochampa W, Rattanatraiwong P (2015) Low power ultrasound-assisted extraction of phenolic compounds from mandarin (citrus reticulata blanco cv. sainampueng) and lime (citrus aurantifolia) peels and the antioxidant. Food Anal Methods 8(5): 11121123.

45. Dranca F, Oroian M (2016) Optimization of ultrasound-assisted extraction of total monomeric anthocyanin (TMA) and total phenolic content (TPC) from eggplant (Solanum melongena L.) peel. Ultrason Sonochem 31: 637-646.

46. Tran KV, Kimura T, Kondo T, Koda S (2014) Quantification of frequency dependence of mechanical effects induced by ultrasound. Ultrason Sonochem 21(2): 716-721.

47.Xin Y, Zhang M, Adhikari B (2014) Ultrasound assisted immersion freezing of broccoli (Brassica oleracea L. var. botrytis L.). Ultrason Sonochem 21(5): 1728-1735.

48. Tsai CC, Chou CH, Liu YC, Hsieh CW (2014) Ultrasound-assisted extraction of phenolic compounds from Phyllanthus emblica L. and evaluation of antioxidant activities. Int J Cosmet Sci 36(5): 471-476.

49. Wei MC, Yang YC, Chiu HF, Hong SJ (2013) Development of a hyphenated procedure of heat-reflux and ultrasound-assisted extraction followed by RP-HPLC separation for the determination of three flavonoids content in Scutellaria barbata D. Don. J Chromatogr B Analyt Technol Biomed Life Sci 940: 126-134.

50. Ma Y, Ye X, Hao Y, Xu G, Xu G, et al. (2008) Ultrasound-assisted extraction of hesperidin from Penggan (Citrus reticulata) peel. Ultrason Sonochem 15(3): 227-232

51. Celli GB, Ghanem A, Brooks MS (2015) Optimization of ultrasoundassisted extraction of anthocyanins from haskap berries (Lonicera caerulea L.) using response surface methodology. Ultrason Sonochem 27: 449-455.

52. Dey S, Rathod VK (2013) Ultrasound assisted extraction of beta-carotene from Spirulina platensis. Ultrason Sonochem 20(1): 271-276.

53. Xie JH, Shen MY, Nie SP, Zhao Q, Li C, et al. (2014) Separation of water- 
soluble polysaccharides from Cyclocarya paliurus by ultrafiltration process. Carbohydr Polym 101: 479-483.

54. Zhang Y, Qiao L, Song M, Wang L, Xie J, et al. (2014) Hplc-ESI-MS/MS analysis of the water-soluble extract from Ziziphi spinosae semen and its ameliorating effect of learning and memory performance in mice. Pharmacogn Mag 10(40): 509-516.

55. Wang J, Sun B, Liu Y, Zhang H (2014) Optimisation of ultrasound-assisted enzymatic extraction of arabinoxylan from wheat bran. Food Chem 150 482-488.

56. Derosa G, Maffioli P (2014) Alkaloids in the nature: pharmacological applications in clinical practice of berberine and mate tea. Curr Top Med Chem 14(2): 200-206.

57. Imperatore C, Aiello A, D’Aniello F, Senese M, Menna M (2014) Alkaloids from marine invertebrates as important leads for anticancer drugs discovery and development. Molecules 19(12): 20391-20423.

58. Pervaiz A, Khan R, Anwar F, Mushtaq G, Kamal MA, et al. (2016) Alkaloids: An Emerging Antibacterial Modality against Methicillin Resistant Staphylococcus aureus. Curr Pharm Des 22(28):4420-4429.

59. Promchai T, Jaidee A, Cheenpracha S, Trisuwan K, Rattanajak R, et al. (2016) Antimalarial oxoprotoberberine alkaloids from the leaves of miliusa cuneata. J Nat Prod 79(4): 978-983.

60. Rujjanawate C, Kanjanapothi D, Panthong A (2003) Pharmacological effect and toxicity of alkaloids from Gelsemium elegans Benth. Ethnopharmacol 89(1): 91-95.

61. Vieira IJ, Medeiros WL, Monnerat CS, Souza JJ, Mathias L, et al. (2008) Two fast screening methods (GC-MS and TLC-ChEI assay) for rapid evaluation of potential anticholinesterasic indole alkaloids in complex mixtures. An Acad Bras Cienc 80(3): 419-426.

62. Zhang L, Geng Y, Duan W, Wang D, Fu M, et al. (2009) Ionic liquid-based ultrasound-assisted extraction of fangchinoline and tetrandrine from Stephaniae tetrandrae. J Sep Sci 32(20): 3550-3554.

63. Hossain MB, Tiwari BK, Gangopadhyay N, O’Donnell CP, Brunton NP, et al. (2014) Ultrasonic extraction of steroidal alkaloids from potato peel waste. Ultrason Sonochem 21(4): 1470-1476.

64. Nowak J, Woźniakiewicz M, Klepacki P, Sowa A, Kościelniak P (2016) Identification and determination of ergot alkaloids in Morning Glory cultivars. Anal Bioanal Chem 408(12): 3093-3102.

65. Klayman DL (1985) Qinghaosu (artemisinin): an antimalarial drug from China. Science 228(4703): 1049-1055

66. White NJ (1997) Assessment of the pharmacodynamic properties of antimalarial drugs in vivo. Antimicrob Agents Chemother 41(7): 14131422.

67. Klayman DL, Lin AJ, Acton N, Scovill JP, Hoch JM, et al. (1984) Isolation of artemisinin (qinghaosu) from Artemisia annua growing in the United States. J Nat Prod 47(4): 715-717.

68. Chemat S, Aissa A, Boumechhour A, Arous O, Ait-Amar H (2017) Extraction mechanism of ultrasound assisted extraction and its effect on higher yielding and purity of artemisinin crystals from Artemisia annua L. leaves. Ultrason Sonochem 34: 310-316.

69. Chen Z, Zou Y, Wang J, Li M, Wen Y (2016) Phytotoxicity of chiral herbicide bromacil: Enantioselectivity of photosynthesis in Arabidopsis thaliana. Sci Total Environ 548-549: 139-147.

70. Niedzwiedzki DM, Hunter CN, Blankenship RE (2016) Evaluating the nature of so-called s*-state feature in transient absorption of carotenoids in light-harvesting complex 2 (LH2) from purple photosynthetic bacteria. J Phys Chem B 120(43): 11123-11131.

71. Rangani J, Parida AK, Panda A, Kumari A (2016) Coordinated changes in antioxidative enzymes protect the photosynthetic machinery from salinity induced oxidative damage and confer salt tolerance in an extreme halophyte Salvadora persica L. Front Plant Sci 7: 50.

72. Ordóñez-Santos LE, Pinzón-Zarate LX, González-Salcedo LO (2015) Optimization of ultrasonic-assisted extraction of total carotenoids from peach palm fruit (Bactris gasipaes) by-products with sunflower oil using response surface methodology. Ultrason Sonochem 27: 560-566.

73. Goula AM, Ververi M, Adamopoulou A, Kaderides K (2017) Green ultrasound-assisted extraction of carotenoids from pomegranate wastes using vegetable oils. Ultrason Sonochem 34: 821-830.

74.Xiong LZ, Ma Q, Long H (2012) Optimization on ultrasonic extraction technology of total coumarines in cortex fraxini. Zhong Yao Cai 35(4): 634-637.

75. Konrad M, Nieman DC (2015) Evaluation of quercetin as a countermeasure to exercise-induced physiological stress. Antioxidants in sport nutrition. M. Lamprecht. Boca Raton (FL).

76. Jiang N, Doseff AI, Grotewold E (2016) Flavones: from biosynthesis to health benefits. Plants (Basel) 5(2)

77. Nakatsuka T, Saito M, Yamada E, Fujita K, Kakizaki Y, et al. (2012) Isolation and characterization of GtMYBP3 and GtMYBP4, orthologues of R2R3MYB transcription factors that regulate early flavonoid biosynthesis, in gentian flowers. J Exp Bot 63(18): 6505-6517.

78. Martinez-Perez C, Ward C, Cook G, Mullen P, McPhail D, et al. (2014) Novel flavonoids as anti-cancer agents: mechanisms of action and promise for their potential application in breast cancer. Biochem Soc Trans 42(4): 1017-1023.

79. Tang Z, Yin R, Bi K, Zhu H, Han F, et al. (2015) Simultaneous quantitative determination of 20 active components in the traditional Chinese medicine formula Zhi-Zi-Da-Huang decoction by liquid chromatography coupled with mass spectrometry: application to study the chemical composition variations in different combinations. Biomed Chromatogr 29(9): 1406-1414.

80. Zheleva-Dimitrova DZh, Balabanova V, Gevrenova R, Doichinova I, Vitkova A (2015) Chemometrics-based approach in analysis of arnicae flos. Pharmacogn Mag 11(4): S538-S544.

81. Pan G, Yu G, Zhu C, Qiao J (2012) Optimization of ultrasound-assisted extraction (UAE) of flavonoids compounds (FC) from hawthorn seed (HS). Ultrason Sonochem 19(3): 486-490.

82. Wang X, Wu Q, Wu Y, Chen G, Yue W, et al. (2012) Response surface optimized ultrasonic-assisted extraction of flavonoids from Sparganii rhizoma and evaluation of their in vitro antioxidant activities. Molecules 17(6): 6769-6783.

83. Tomaz I, Maslov L, Stupić D, Preiner D, Ašperger D, et al. (2016) Multiresponse optimisation of ultrasound-assisted extraction for recovery of flavonoids from red grape skins using response surface methodology. Phytochem Anal 27(1): 13-22.

84. Hassellund SS, Flaa A, Sandvik L, Kjeldsen SE, Rostrup M (2012) Effects of anthocyanins on blood pressure and stress reactivity: a double-blind randomized placebo-controlled crossover study. J Hum Hypertens 26(6): 396-404

85. Sehitoglu MH, Farooqi AA, Qureshi MZ, Butt G, Aras A (2014) Anthocyanins: targeting of signaling networks in cancer cells. Asian Pac J Cancer Prev 15(5): 2379-2381.

86. Cassidy A, Rogers G, Peterson JJ, Dwyer JT, Lin H, et al. (2015) Higher dietary anthocyanin and flavonol intakes are associated with antiinflammatory effects in a population of US adults. Am J Clin Nutr 102(1): 172-181.

87. Zou TB, Wang M, Gan RY, Ling WH (2011) Optimization of ultrasoundassisted extraction of anthocyanins from mulberry, using response surface methodology. Int J Mol Sci 12(5): 3006-3017.

88. He B, Zhang LL, Yue XY, Liang, Jiang J, et al. (2016) Optimization of ultrasound-assisted extraction of phenolic compounds and anthocyanins from blueberry (Vaccinium ashei) wine pomace. Food Chem 204: 70-76.

89. Sang J, Ma Q, Hou XF, Li CQ (2017) Extraction optimization and identification of anthocyanins from Nitraria tangutorun Bobr. seed meal and establishment of a green analytical method of anthocyanins. Food Chem 218: 386-395. 
90. Yang J, Yang X, Li M (2012) Baicalin, a natural compound, promotes regulatory T cell differentiation. BMC Complement Altern Med 12: 64.

91. He XW, Yu D, Li WL, Zheng Z, Lv CL, et al. (2016) Anti-atherosclerotic potential of baicalin mediated by promoting cholesterol efflux from macrophages via the PPARgamma-LXRalpha-ABCA1/ABCG1 pathway. Biomed Pharmacother 83: 257-264.

92. Zhang K, Pan X, Wang F, Ma J, Su G, et al. (2016) Baicalin promotes hippocampal neurogenesis via SGK1- and FKBP5-mediated glucocorticoid receptor phosphorylation in a neuroendocrine mouse model of anxiety/depression. Sci Rep 6: 30951.

93. Wang J, Ji SY, Liu SZ, Jing R, Lou WJ (2015) Cardioprotective effect of breviscapine: inhibition of apoptosis in $\mathrm{H} 9 \mathrm{c} 2$ cardiomyocytes via the PI3K/Akt/eNOS pathway following simulated ischemia/reperfusion injury. Pharmazie 70(9): 593-597.

94. Liu X, Yao L, Sun D, Zhu X, Liu Q, et al. (2016) Effect of breviscapine injection on clinical parameters in diabetic nephropathy: A metaanalysis of randomized controlled trials. Exp Ther Med 12(3): 13831397.

95. He ME, Wang W, Wu LS, Gao YT, Li SY (2010) Study on the extraction of breviscapine from Erigeron breviscapus with ultrasonic wave technology optimized by central composite design-response surface method. Zhong Yao Cai 33(6): 984-988.

96. Yeung DK, Leung SW, Xu YC, Vanhoutte PM, Man RY (2006) Puerarin, an isoflavonoid derived from Radix puerariae, potentiates endotheliumindependent relaxation via the cyclic AMP pathway in porcine coronary artery. Eur J Pharmacol 552(1-3): 105-111.

97. Jintao X, Quanwei Y, Yun J, Yufei L, Chunyan L, et al. (2016) Rapid determination of puerarin by near-infrared spectroscopy during percolation and concentration process of puerariae lobatae radix Pharmacogn Mag 12(47): 188-192.

98. Fan JP, Cao J, Zhang XH, Huang JZ, Kong T, et al. (2012) Optimization of ionic liquid based ultrasonic assisted extraction of puerarin from Radix Puerariae Lobatae by response surface methodology. Food Chem 135(4): 2299-2306.

99. Wu Y, Wang X, Fan E (2012) Optimisation of ultrasound-assisted extraction of puerarin and total isoflavones from Puerariae Lobatae Radix (Pueraria lobata (Wild.) Ohwi) with response surface methodology. Phytochem Anal 23(5): 513-519.

100. Diederich M, Muller F, Cerella C (2016) Cardiac glycosides: From molecular targets to immunogenic cell death. Biochem Pharmaco 125: $1-11$

101. Xue Z, Yang B (2016) Phenylethanoid glycosides: research advances in their phytochemistry, pharmacological activity and pharmacokinetics. Molecules 21(8).

102. Oerther SE (2011) Plant poisonings: common plants that contain cardiac glycosides. J Emerg Nurs 37(1): 102-103.

103. Cai X, Zhang R, Guo Y, He J, Li S, et al. (2015) Optimization of ultrasoundassisted extraction of gardenia fruit oil with bioactive components and their identification and quantification by HPLC-DAD/ESI-MS (2). Food Funct 6(7): 2194-2204

104. Wang J, Miao M, Qu L, Cui Y, Zhang Y (2016) Protective effects of geniposide against Tripterygium glycosides (TG)-induced liver injury and its mechanisms. J Toxicol Sci 41(1): 165-173.

105. Huang H, Zhang X, Huang Z, Zhang Y, Zhou Z (2017) Geniposide reverses multidrug resistance in vitro and in vivo by inhibiting the efflux function and expression of P-glycoprotein. Exp Ther Med 13(2): 437-442.

106. Hao J, Yang X, Ding X, Guo LM, Zhu CH, et al. (2016) Paeoniflorin potentiates the ihibitory effects of erlotinib in pancreatic cancer cell lines by reducing ErbB3 phosphorylation. Sci Rep 6: 32809

107. Liu H, Yu C, Xu T, Zhang X, Dong M (2016) Synergistic protective effect of paeoniflorin and beta-ecdysterone against rotenone-induced neurotoxicity in PC12 cells. Apoptosis 21(12):1354-1365.
108. Xie XM, Yu CZ, Xu H, Wang S, Wang DL, et al. (2004) Quality evaluation of prepared slices of Paeonia lactiflon--determination of paeoniflorin by HPLC. Zhongguo Zhong Yao Za Zhi 29(8): 759-762.

109. Xia EQ, Ai XX, Zang SY, Guan TT, Xu XR, et al. (2011) Ultrasound-assisted extraction of phillyrin from Forsythia suspensa. Ultrason Sonochem 18(2): 549-552.

110. Wei T, Tian W, Yan H, Shao G, Xie G (2014) Protective effects of phillyrin on H2O 2-induced oxidative stress and apoptosis in PC12 cells. Cell Mol Neurobiol 34(8): 1165-1173.

111. Qu XY, Li QJ, Zhang HM, Zhang XJ, Shi PH, et al. (2016) Protective effects of phillyrin against influenza A virus in vivo. Arch Pharm Res 39(7): 998-1005.

112. Kang JS, Kim SO, Kim GY, Hwang HJ, Kim BW, et al. (2016) An exploration of the antioxidant effects of garlic saponins in mouse-derived C2C12 myoblasts. Int J Mol Med 37(1): 149-156.

113. Koczurkiewicz P, Kowolik E, Podolak I, Wnuk D, Piska K, et al. (2016) Synergistic cytotoxic and anti-invasive effects of mitoxantrone and triterpene saponins from lysimachia ciliata on human prostate cancer cells. Planta Med 82(18):1546-1552.

114. Wu J, Lin L, Chau FT (2001) Ultrasound-assisted extraction of ginseng saponins from ginseng roots and cultured ginseng cells. Ultrason Sonochem 8(4): 347-352.

115. Liu CT, Wu CY, Weng YM, Tseng CY (2005) Ultrasound-assisted extraction methodology as a tool to improve the antioxidant properties of herbal drug Xiao-chia-hu-tang. J Ethnopharmacol 99(2): 293-300.

116. Adfa M, Rahmad R, Ninomiya M, Yudha SS, Tanaka K, et al. (2016) Antileukemic activity of lignans and phenylpropanoids of Cinnamomum parthenoxylon. Bioorg Med Chem Lett 26(3): 761-764.

117. Hu P, Li DH, Hu X, Li SG, Sai CM, et al. (2016) Lignans and triterpenoids from Vitex negundo var. heterophylla and their biological evaluation. Fitoterapia 111: 147-153.

118. Li CP, Qiu GZ, Liu B, Chen JL, Fu HT (2016) Neuroprotective effect of lignans extracted from Eucommia ulmoides Oliv. on glaucoma-related neurodegeneration. Neurol Sci 37(5): 755-762.

119. Teponno RB, Kusari S, Spiteller M (2016) Recent advances in research on lignans and neolignans. Nat Prod Rep 33(9): 1044-1092.

120. Zhang L, Wang X (2010) Hydrophobic ionic liquid-based ultrasoundassisted extraction of magnolol and honokiol from cortex Magnoliae officinalis. J Sep Sci 33(13): 2035-2038.

121. Guo YX, Han J, Zhang DY, Wang LH, Zhou LL (2013) Aqueous two-phase system coupled with ultrasound for the extraction of lignans from seeds of Schisandra chinensis (turcz.) Baill. Ultrason Sonochem 20(1) 125-132.

122. Guo T, Su D, Huang Y, Wang Y, Li YH, et al. (2015) Ultrasound-Assisted Aqueous Two-Phase System for Extraction and Enrichment of Zanthoxylum armatum Lignans. Molecules 20(8): 15273-15286.

123. Li YL, Yeung CM, Chiu LC, Cen YZ, Ooi VE (2009) Chemical composition and antiproliferative activity of essential oil from the leaves of a medicinal herb, Schefflera heptaphylla. Phytother Res 23(1): 140-142.

124. Kasrati A, Jamali CA, Bekkouche K, Lahcen H, Markouk M, et al (2013) Essential oil composition and antimicrobial activity of wild and cultivated mint timija (Mentha suaveolens subsp. timija (Briq.) Harley), an endemic and threatened medicinal species in Morocco. Nat Prod Res 27(12): 1119-1122.

125. WangchukP,KellerPA,PyneSG, Taweechotipatr M,Kamchonwongpaisan S (2013) GC/GC-MS analysis, isolation and identification of bioactive essential oil components from the Bhutanese medicinal plant, Pleurospermum amabile. Nat Prod Commun 8(9): 1305-1308.

126. Uma K, Huang X, Kumar BA (2016) Antifungal effect of plant extract and essential oil. Chin J Integr Med. 23(3): 233-239.

127. Yang B, Chen J, Lee FS, Wang X (2008) GC-MS fingerprints for discrimination of Ligusticum chuanxiong from Angelica. J Sep Sci 31(18): 3231-3237. 
128. Da Porto C, Porretto E (2013) Comparison of ultrasound-assisted extraction with conventional extraction methods of oil and polyphenols from grape (Vitis vinifera L.) seeds. Ultrason Sonochem 20(4): 10761080 .

129. Samaram S, Mirhosseini H, Tan CP, Ghazali HM (2013) Ultrasoundassisted extraction (UAE) and solvent extraction of papaya seed oil yield, fatty acid composition and triacylglycerol profile. Molecules 18(10): 12474-12487.

130. Zhang LG, Wang FX, Ni LJ, Wang YL, Yang YJ, et al. (2012) Extraction technology optimization and quality analysis of volatile oil in Rhizoma Curcumae. Zhong Yao Cai 35(3): 471-475.

131. Huang WY, Cai YZ, Zhang Y (2010) Natural phenolic compounds from medicinal herbs and dietary plants: potential use for cancer prevention. Nutr Cancer 62(1): 1-20.

132. Wang J, Zhao YM, Tian YT, Yan CL, Guo CY (2013) Ultrasound-assisted extraction of total phenolic compounds from Inula helenium. Scientific World Journal 2013: 157527.

133. de Morais Rodrigues MC, Borges LL, Martins FS, Mourão RH, da Conceição EC (2016) Optimization of Ultrasound-assisted Extraction of Phenolic Compounds from Myrcia amazonica DC. (Myrtaceae) Leaves. Pharmacogn Mag 12(45): 9-12.

134. LiuJY, Feng CP, LiX, Chang MC, MengJL, etal. (2016) Immunomodulatory and antioxidative activity of Cordyceps militaris polysaccharides in mice. Int J Biol Macromol 86: 594-598.

135. Liu L, Nie S, Xie M (2016) Tumor microenvironment as a new target for tumor immunotherapy of polysaccharides. Crit Rev Food Sci Nutr 56(1): S85-S94.

136. Wang Y, Chen Y, Du H, Yang J, Ming K, et al. (2016) Comparison of the anti-duck hepatitis A virus activities of phosphorylated and sulfated Astragalus polysaccharides. Exp Biol Med (Maywood). 242(3): 344 353.

137. Wang C, Feng L, Su J, Cui L, Dan Liu, et al. (2017) Polysaccharides from Epimedium koreanum Nakai with immunomodulatory activity and inhibitory effect on tumor growth in LLC-bearing mice. J Ethnopharmacol 207: 8-18.

138. Chen C, You LJ, Abbasi AM, Fu X, Liu RH (2015) Optimization for ultrasound extraction of polysaccharides from mulberry fruits with antioxidant and hyperglycemic activity in vitro. Carbohydr Polym 130: 122-132.

139. Jia X, Zhang C, Hu J, He M, Bao J, et al. (2015) Ultrasound-Assisted Extraction, Antioxidant and Anticancer Activities of the Polysaccharides from Rhynchosia minima Root. Molecules 20(11): 20901-20911.

140. Zhang DY, Wan Y, Xu JY, Wu GH, Li L, et al. (2016) Ultrasound extraction of polysaccharides from mulberry leaves and their effect on enhancing antioxidant activity. Carbohydr Polym 137: 473-479.

141. Zheng Q Ren D, Yang N, Yang X (2016) Optimization for ultrasoundassisted extraction of polysaccharides with chemical composition and antioxidant activity from the Artemisia sphaerocephala Krasch seeds. Int J Biol Macromol 91: 856-866.

142. Eliaz I, Weil E, Wilk B (2007) Integrative medicine and the role of modified citrus pectin/alginates in heavy metal chelation and detoxification--five case reports. Forsch Komplementmed 14(6): 358 364.

143. Delphi L, Sepehri H (2016) Apple pectin: A natural source for cancer suppression in $4 \mathrm{~T} 1$ breast cancer cells in vitro and express p53 in mouse bearing 4T1 cancer tumors, in vivo. Biomed Pharmacother 84: 637-644.

144. Ueberall MA, Lorenzl S, Lux EA, Voltz R, Perelman M (2016) Efficacy, safety and tolerability of fentanyl pectin nasal spray in patients with breakthrough cancer pain. J Pain Res 9: 571-585.

145. Wang M, Huang B, Fan C, Zhao K, Hu H, et al. (2016) Characterization and functional properties of mango peel pectin extracted by ultrasound assisted citric acid. Int J Biol Macromol 91: 794-803.
146. Moorthy IG, Maran JP, Ilakya S, Anitha SL, Sabarima SP, et al. (2017) Ultrasound assisted extraction of pectin from waste Artocarpus heterophyllus fruit peel. Ultrason Sonochem 34: 525-530.

147. Hematian SA, Koocheki A, Elahi M (2016) Ultrasound-assisted extraction of beta-d-glucan from hull-less barley: Assessment of physicochemical and functional properties. Int J Biol Macromol. 95:462-475

148. Kuthubutheen J, Smith L Hwang E, Lin V (2016) Preoperative steroids for hearing preservation cochlear implantation: A review. Cochlear Implants Int 17(2): 63-74.

149. McCabe PS, Maricar N, Parkes MJ, Felson DT, O’Neill TW (2016) The efficacy of intra-articular steroids in hip osteoarthritis: a systematic review. Osteoarthritis Cartilage 24(9): 1509-1517.

150. Zubair MS, Al-Footy KO, Ayyad SE, Al-Lihaibi SS, Alarif WM, et al (2016) A review of steroids from Sarcophyton species. Nat Prod Res 30(8): 869-879.

151. Matsumoto S, Varela RM, Palma M, Molinillo JM, Lima IS, et al. (2014) Bio-guided optimization of the ultrasound-assisted extraction of compounds from Annona glabra L. leaves using the etiolated wheat coleoptile bioassay. Ultrason Sonochem 21(4): 1578-1584.

152. Lemstrova R, Melichar B, Mohelnikova-Duchonova B (2016) Therapeutic potential of taxanes in the treatment of metastatic pancreatic cancer. Cancer Chemother Pharmacol 78(6): 1101-1111.

153. Chen X, Liao Y, Long D, Yu T, Shen F, et al. (2017) The Cdc2/Cdk1 inhibitor, purvalanol A, enhances the cytotoxic effects of taxol through Op18/stathmin in non-small cell lung cancer cells in vitro. Int J Mol Med 40(1): 235-242.

154. Dong QF, Liu JJ, Yu RM (2010) Taxol content comparison in different parts of Taxus madia and Taxus chinensis var. mairei by HPLC. Zhong Yao Cai 33(7): 1048-1051

155. Mayol M, Riba M, González-Martínez SC, Bagnoli F, de Beaulieu JL, et al. (2015) Adapting through glacial cycles: insights from a long-lived tree (Taxus baccata). New Phytol 208(3): 973-986.

156. Liu WC, Gong T, Zhu P (2016) Advances in exploring alternative taxol sources. RSC Advances 6: 48800-48809.

157. Kim GJ, Kim JH (2015) Enhancement of extraction efficiency of paclitaxel from biomass using ionic liquid-methanol co-solvents under acidic conditions. Process Biochemistry 50(6): 989-996.

158. Xiao L, Lao WG, Tan Y, Qu X (2012) In vitro investigation of anti-diabetic effect of Taxus cuspidate extracts by ultrasound assisted method. Am J Chin Med 40(6): 1205-1215.

159. Meullemiestre A, Petitcolas E, Maache-Rezzoug Z, Chemat F, Rezzoug SA (2016) Impact of ultrasound on solid-liquid extraction of phenolic compounds from maritime pine sawdust waste. Kinetics, optimization and large-scale experiments. Ultrason Sonochem 28: 230-239.

160. Nour V, Trandafir I, Cosmulescu S (2016) Optimization of ultrasoundassisted hydroalcoholic extraction of phenolic compounds from walnut leaves using response surface methodology. Pharm Biol 54(10): 21762187.

161. Alves Monteath SAF, Maciel MAM, Vega RG, de Mello H, de Araújo Martins C (2017) Ultrasound-assisted extraction of ursolic acid from the flowers of ixora coccinia linn (rubiaceae) and antiproliferative activity of ursolic acid and synthesized derivatives. Pharmacogn Mag 13(50): 265-269.

162. Wang J, Lu HD, Muḥammad U, Han JZ, Wei ZH, et al. (2016) Ultrasoundassisted extraction of polysaccharides from Artemisia selengensis Turcz and its antioxidant and anticancer activities. J Food Sci Technol 53(2): 1025-1034

163. Ghitescu RE, Volf I, Carausu C, Bühlmann AM, Gilca IA, et al. (2015) Optimization of ultrasound-assisted extraction of polyphenols from spruce wood bark. Ultrason Sonochem 22: 535-541.

164. Chemat F, Rombaut N, Sicaire AG, Meullemiestre A, Fabiano-Tixier AS, et al. (2017) Ultrasound assisted extraction of food and natura 
products. Mechanisms, techniques, combinations, protocols and applications. A review. Ultrason Sonochem 34: 540-560.

165. Espada-Bellido E, Ferreiro-González M, Carrera C, Palma M, Barroso CG, et al. (2017) Optimization of the ultrasound-assisted extraction of anthocyanins and total phenolic compounds in mulberry (Morus nigra) pulp. Food Chem 219: 23-32.

166. Saleh IA, Vinatoru M, Mason TJ, Abdel-Azim NS, Aboutabl EA, et al. (2016) A possible general mechanism for ultrasound-assisted extraction (UAE) suggested from the results of UAE of chlorogenic acid from Cynara scolymus L. (artichoke) leaves. Ultrason Sonochem 31: 330-336.

167. Liu W, Li DD, Yang HS, Chen YY, Wei JF, et al. (2015) Determination of oleanic acid and paeoniflorin in Paeonia lactiflora by ultrasoundassisted ionic liquid-reversed phase liquid chromatography. Zhongguo Zhong Yao Za Zhi 40(3): 443-449.

168. Liu Y, Wei S, Liao M. (2013) Optimization of ultrasonic extraction of phenolic compounds from Euryale ferox seed shells using response surface methodology. Ind Crops Prod 29: 837-843.
169. Schinor EC, Salvador MJ, Turatti IC, Zucchi OL, Dias DA (2004) Comparison of classical and ultrasound-assisted extractions of steroids and triterpenoids from three Chresta spp. Ultrason Sonochem 11(6): 415-421.

170. Tan Z, Wang C, Yi Y, Wang H, Li M, et al. (2014) Extraction and purification of chlorogenic acid from ramie (Boehmeria nivea $\mathrm{L}$. Gaud) leaf using an ethanol/salt aqueous two-phase system. Sep Purif Technol 132(20): 396-400.

171. Wang K, Li M, Wen X, Chen X, He Z, et al. (2018) Optimization of ultrasound-assisted extraction of okra (Abelmoschus esculentus (L.) Moench) polysaccharides based on response surface methodology and antioxidant activity. Int J Biol Macromol 114: 1056-1063.

172. Wang Z, He Z, Zhao Z, Yi S, Mu J (2017) Influence of ultrasound-assisted extraction on the pyrolysis characteristics and kinetic parameters of eucalyptus. Ultrason Sonochem 37: 47-55.

173. Wu J, Nyborg WL (2008) Ultrasound, cavitation bubbles and their interaction with cells. Adv Drug Deliv Rev 60(10): 1103-1116. 